\title{
The Effect of Hydrotherapy Training on Function Occupational Toofal Sanat Consulting Engineers
}

\author{
Dolatabadi $\mathbf{N H}^{1 *}$, Rahnama $\mathbf{N}^{1}$ and Tavakol \\ $\mathbf{N}^{2}$ \\ ${ }^{1}$ Departmnet of Sport Science, Islamic Azad University, \\ Isfahan (Khorasgan) Branch, Iran \\ ${ }^{2}$ Gastrointestinal and Hepatobiliary Diseases Research \\ Center, Poursina Hakim Research Institute for Health \\ Care Development, Isfahan, Iran \\ *Correspondling author: Heidari Dolatabadi N, \\ Faculty of Sport Science, Islamic Azad University, Isfahan \\ (Khorasgan) Branch, Iran
}

Received: February 06, 2016; Accepted: March 14, 2017; Published: March 20, 2017

\begin{abstract}
The aim of this study was the effect of hydrotherapy training on health function, motion and occupational. Sixty-one full time police personnel of The Islamic Republic of Iran participated in this study. Subject assigned into hydrotherapy (age: $38.4+7.4$ years, height: $170.3+6.8 \mathrm{~cm}$, weight: $77.6+8.1 \mathrm{~kg}$ ). The Nordic Musculo-skeletal Questionnaire was used to study the prevalence of MSD. After primarily evaluations from 61 personnel, thirty personnel identified as having MSD involved in corrective exercise program for 8 weeks (3 sessions per week, each session 60 minutes). Before initiation of hydrotherapy and after completion of the course, data were collected. Covariance Test was used to show differences at significance level of $(P<0.05)$. Regarding MSD, a significant difference between different sites of body was found $(P<0.05)$; low back $(43 \%)$, knee $(24 \%)$ shoulder $(13 \%)$ and neck (18\%) were the most prevalent sites. The severity and rate of disorders decreased significantly following 8-weeks training in low back, shoulder, knee and neck areas $(P<0.05)$. It can be concluded that prevalence of MSD among the police personnel was relatively high and hydrotherapy training was effective to decrease it. So, hydrotherapy for reducing risk level would be recommended.
\end{abstract}

Keywords: Musculoskeletal disorders; Hydrotherapy; Pain; Toofal Sanat

\section{Introduction}

Work is an inseparable part of human's life, but as developing science and technology, increase side effects and occupational illnesses. Among these musculoskeletal illnesses (problems, diseases) allocate main occupational illnesses to itself, and consider the most prevalence diseases [1]. Work environment have a main role in prevalence of many musculoskeletal injuries, even though many of these problems are avoidable with more observing and attention to ergonomic principles or at least can be reduced [2]. In industrial developing countries, work's place hurts and problems are so serious [3]. Poor work condition and the lack of presenting effective prevention programs from work injuries, increase musculoskeletal disorders rate in industrial developing countries [4]. In industrial developing countries, work places problems and injuries are so serious [3]. Musculoskeletal disorders related to work regarded as a main health, disability and absence from work problems in industrial societies, that allocated about one-third health care costs to itself [5], also causes body's structure destruction like muscles, joints, tendons, ligaments, nerves, bones and blood circulating system [6]. These disorders involve wide range of inflammation and destructive problems and illnesses that leads to pain and weakening function [7]. Some body's area like back, neck, shoulder, arm and forearm are more prone to hurt and in performed studies, lower limbs are considered more [8]. Risk's factor of musculoskeletal generally includes occupational and non-occupational factors [9].

Occupational risk factors involve physic needs and task execution with inappropriate posture of applied force, repeated motions, duty period and vibration. Non-occupational or individual factors also include age, sex, muscle strength (power), physics readiness and mental-social factors such as time and work pressure, absence of social support and lack of occupational satisfaction [10]. Among aforementioned factors, inappropriate posture regarded as the most important cases [11].

Musculoskeletal disorder work has close relationship with posture during. Neck, back, shoulder, fore arm and knee are organs that exposure to the most side effects resulted from awkward posture. Performing (executing, doing) work with inappropriate posture leads to posture pressure, tiredness, pain; as if it is possible that one force to stop working and take rest. In previous studies, researchers investigate cases such as studying the relationship between neck pain and long- time shoulder pain with posture disorders (lordosis) and inappropriate posture during sitting, relationship between spine's posture and long time back pain and increasing lordosis of back area, inappropriate posture and relationship with mental pressures and musculoskeletal problems signs, the relationship between (among) posture during sitting and spinal cord curvature, posture, and back pain and usually pointed to significance relationship among the prevalence pf pain and poor posture [12-16].

For instance Soderberg [17] reported that work type and one's posture during work have a direct effect on increasing or reducing Kyphosis and lordosis arcs [17]. Later (next) studies also show occupational factors effects on creating posture's disorders and also joint and muscles and bones pain [18] Proceedings of the first seminar on the development of health in works [19].

Back pain is one of the most common healthy problems related to work in industrial developing countries [20]. More than $80 \%$ of persons experience this pain at least one time during its life [21]. Therapeutic training widely considered as one of the suitable interventions in 
back pain treatment And return to work in occupational cares [22]. Therapeutic training more effectively known than to rest on bed [23]. Numerous researches (studies) show therapeutic training effect on reducing back, shoulder and upper limb [24,25].

Generally, physical activities and exercise regarded as one of the basic methods of care in facing with musculoskeletal chronic pains.

One of the common and useful applications of water is hydrotherapy. Hydrotherapy means illness treatment through water. Since it's remembered, both primary tribes and civilized nations use water for treatment, even wild and pet animals founded that, when they become ill, they should drink water. In fact, human beings realized (understand) hydrotherapy power and potency in providing body's and spirits relaxation many centuries. Hydrotherapy considered with Iranian, Japanese, Egyptian and Greeks according to many proprieties, and used more. Perhaps easy and more convenient tools that people used for refreshment. Illness, getting lull and convenience, is water. Hydrotherapy is the popular method and contrary to most other methods of muscle refreshment coincident with person's (individual) satisfaction and happy.

Various training are done in hydrotherapy pools that have a good consequences, such as, walking and running water without the help of various tools are more useful than other activities. Horizontal movement toward front and back (rear) is so useful for arm and hip joints.

Water stream's temperature and intensity can be variable upon professional application from this method. Water temperature along with water stream can be effective in muscle calm down and their relief. Warm water causing blood to reach damaged tissue.

Increasing blood stream reach oxygen and needed material staff to tissues and excreted cell's waste material. Warm water cause muscle spasms reducing and relieving pain and increase range of motion. Cold water, cause blood stream slow-down, that this slowdown is effective in reducing inflammation, pain, muscle spasms. Besides positive effects on musculoskeletal system leads to decrease pain feeling. Due to this important that posture in work activities are of importance, and considered as one of the main factors of musculoskeletal disorders, we try to investigate hydrotherapy advantages on health, motion, occupation performance of tofal sanat consulting engineers desk staffs for this purpose, 30 men about 30 men about 30 years old selected randomly and hydrotherapy trainings considered for them [26].

\section{Research's Methodology}

This study of semi-experimental type (kind) performed (done) with pre-test post- test design (model) with one training intervention group and one control group. 30 men selected and an available sampling and upon disorders evaluation criterion. Test's subjects work 12 hours from 7:00AM until 7:00PM daily.

Elimination criteria from research were current surgery, existing any musculoskeletal problem (like fracture), existing any undetermined pathology also persons (who) knows about its illnesses before performing studying and/ or upon doctor's recommendation had attempted to carryout measures for treatment, remove among samples before beginning study, all subjects sign testimonial for
Table 1: Frequency percentage of skeletal disorders in neck, back, shoulder and knee.

\begin{tabular}{|c|c|c|}
\hline Disorder & Frequency & Percentage \\
\hline Neck & 14 & $18 \%$ \\
\hline Back & 32 & $43 \%$ \\
\hline Shoulder & 10 & $13 \%$ \\
\hline Knee & 18 & $24 \%$ \\
\hline Totally & 74 & $100 \%$ \\
\hline
\end{tabular}

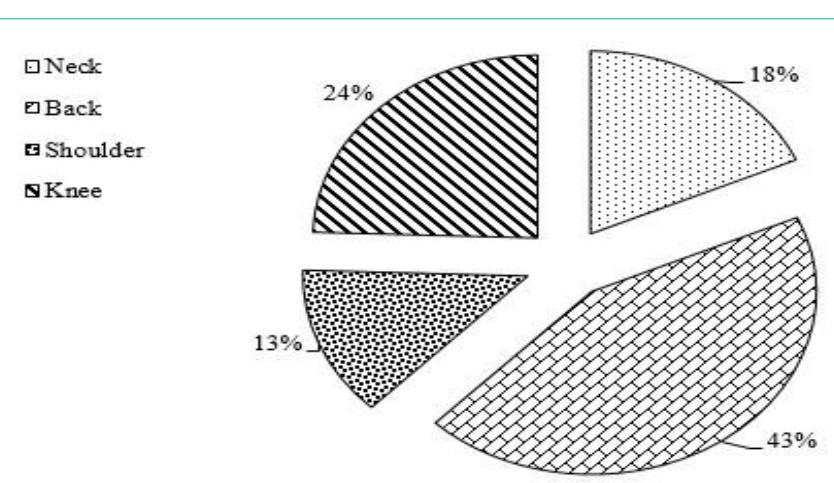

Figure 1: Information related to musculoskeletal frequency.

attending in researcher's tests and then during one session describe the method of performing tests. For performing pre-test, height and weight of each subjects measured 24 hours before performing training. For occupational evaluations was (with) Nordic questionnaire. In this study, with regards to the main principles of suitable (appropriate) training in this field, special training program are adjusted that applied after expert's review and approval and presented trainings.

Scheduling of each sport session in water include warm up, main activities and cool down, and performed with or without assistant tools such as special swimming belts, shoes, glove, wrist special bracelet, load (weight) or special water's dumbbell, water step, swim board, rubber band, ball and etc. as individual, group, double activities. In this research, all the trainings done completely in pool's deep part from beginning to end during quarterly.

Applied protocol is a training protocol that design upon study's purpose and include three parts: warm-up training (adaptation with water), main training, cool down that the time of executing training was one hour in each session that the first 15 minutes allocated to tensile training and walking in water, and in next thirty minutes, main trainings means balance training and strength powerful and flexibility in water are done. In the last 15 minutes, subjects (participants) performed returning movements to primary state and cool-down. This protocol executed 3 sessions in weeks and for 8 minutes.

In this study used description statistic for describing statistics of variables and variance analysis test for information analysis. Statistical analysis performed through SPESS16 software. Significance level considered lower than 0.05 .

\section{Research's Findlings}

61 people selected from tofal sanat consulting engineers company as purposeful (age: $38.4+4$, height: $170.3+6.8 \mathrm{~cm}$, weight: $77.6+8.1 \mathrm{~kg}$ ). For studying musculoskeletal disorders, Nordic 
Table 2: Information related to skeletal disorders in neck points.

\begin{tabular}{|c|c|c|c|c|c|c|}
\hline & \multicolumn{2}{|c|}{ Before modification training } & \multicolumn{2}{|c|}{ After modification training } & \multirow{2}{*}{ Percentage } & \multirow{2}{*}{ P-Value } \\
\hline & Number & Percentage & Number & Percentage & & \\
\hline Mild & 50 & 7 & 0.5 & 2 & 71.4 decreased & \multirow{4}{*}{0.041} \\
\hline Severe & 28.5 & 4 & 0.25 & 1 & 75 decreased & \\
\hline So severe & 21.5 & 3 & 0.25 & 1 & 66.6 decreased & \\
\hline Total & 100 & 14 & 100 & 4 & 71.4 decreased & \\
\hline
\end{tabular}

Table 3: Information related to skeletal disorders in shoulder points.

\begin{tabular}{|c|c|c|c|c|c|c|}
\hline & \multicolumn{2}{|c|}{ Before modification training } & \multicolumn{2}{|c|}{ After modification training } & \multirow{2}{*}{ Percentage } & \multirow{2}{*}{ P-Value } \\
\hline & Number & Percentage & Number & Percentage & & \\
\hline Mild & 30 & 3 & 33.3 & 1 & 66.6 decreased & \multirow{4}{*}{0.038} \\
\hline Severe & 50 & 5 & 33.3 & 1 & 80 decreased & \\
\hline So severe & 20 & 2 & 33.3 & 1 & 50 decreased & \\
\hline Total & 100 & 10 & 100 & 3 & 70 decreased & \\
\hline
\end{tabular}

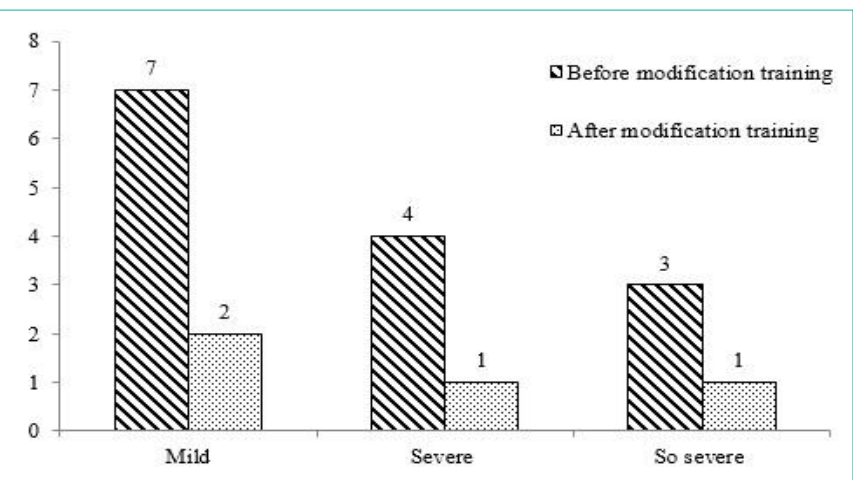

Figure 2: Information related to skeletal disorders in neck points.



Figure 3: Information related to skeletal disorders in shoulder points.

questionnaire are used. Information related to skeletal disorders related to neck, back, shoulder and knee point, presented in Table 1. There is significance difference among different areas in body about musculoskeletal disorders prevalence. The most frequent are in back area with $43 \%$ frequency, then in knee with $24 \%$ frequency, neck with $18 \%$ frequency and last in shoulder with $13 \%$ frequency (Figure 1). Following table is information related to neck disorders after and before 8 weeks hydrotherapy trainings. According to achieved significance level $(\mathrm{z}=2.65, \mathrm{p} \leq 0.05)$ and comparing it on 0.05 level, we have zero hypothesis refusal. It means that after modification trainings, neck disorders significantly reduced and gaining health percentage is $71.4 \%$ (Table 2, Figure 2).

Following Table 3 is related to shoulder disorders before and after 8 weeks hydrotherapy trainings (Figure 3 ).

With regards to achieved significance levels $(\mathrm{z}=2.91, \mathrm{p} \leq 0.05)$ and compare it on 0.05 level, we have zero hypothesis refusal. It means that after modification trainings, shoulder disorders significantly reduced, gaining in health are $70 \%$. Following table is information related to back disorders before and after 8 week's hydrotherapy raining. With regards to achieved significance level $(\mathrm{z}=2.68, \mathrm{p} \leq 0.05)$ and compare it in 0.05 level, we have zero hypothesis refusal. It means that after modification, back disorder significantly decreased gaining in health percentage is $78.1 \%$ (Figure 4 ).

Following Table 4 is the information related to knee disorders after and before 8 weeks hydrotherapy trainings. With regards to achieved significance level $(\mathrm{z}=2.76, \mathrm{p} \leq 0.05)$ and comparing it in 0.05 level, we have zero hypothesis refusal. It means that after modification, knee disorders significantly decreased gaining in health is $83.3 \%$ (Figure 5).

\section{Discussion and Conclusion}

In current research, a total 61 person (people) are evaluated about musculoskeletal disorders. 30 people have disorder. In this study about musculoskeletal disorders prevalence, back area allocated the most disorders to itself. These results match with Bos et al [27], Alexopoulos et al [28], Rahnama et al [29], Jan bozorgi et al [30], Latifipour et al [31] that in its studies allocated the most prevalence rate of musculoskeletal disorders to back, and don't match with Chubineh studies [1] in dentists. In studying current occupations in company's staff, especially in technical section, it is observed that most works performed as sitting and standing in stable and uniform, with regards to that in some of occupations, persons forced to bend forward it's neck and work in such status for long- time leads to musculoskeletal disorders and in some occupations, person used hands for object carrying and displacement and in addition to the lack of agronomy principles and standards compliance of tools and equipments and poor design and improper layout of work station leads person, work with inappropriate posture as result, it provides back ground for musculoskeletal disorders. With regards to that 
Table 4: information related to skeletal disorders in back points.

\begin{tabular}{|c|c|c|c|c|c|}
\hline & \multicolumn{2}{|c|}{ Before modification training } & \multicolumn{2}{|c|}{ After modification training } & P-Value \\
\cline { 2 - 5 } & Number & Percentage & Number & Percentage \\
\hline Mild & 37.5 & 12 & 42 & 3 & 75 decreased \\
\hline Severe & 37.5 & 12 & 42 & 3 & 75 decreased \\
\hline So severe & 25 & 8 & 16 & 1 & 7.026 \\
\hline Total & 100 & 12 & 100 & 78.1 decreased \\
\hline
\end{tabular}

Table 5: Information related to skeletal disorders in knee points.

\begin{tabular}{|c|c|c|c|c|c|c|}
\hline & \multicolumn{2}{|c|}{ Before modification training } & \multicolumn{2}{|c|}{ After modification training } & \multirow{2}{*}{ Percentage } & \multirow{2}{*}{ P-Value } \\
\hline & Number & Percentage & Number & Percentage & & \\
\hline Mild & 33.3 & 6 & 33.4 & 1 & 83.3 decreased & \multirow{4}{*}{0.034} \\
\hline Severe & 16.7 & 3 & 0 & 0 & 100 decreased & \\
\hline So severe & 50 & 9 & 66.6 & 2 & 77.7 decreased & \\
\hline Total & 100 & 18 & 100 & 3 & 83.3 decreased & \\
\hline
\end{tabular}



Figure 4: Information related to skeletal disorders in back point.

musculoskeletal disorders prevalence rate in firm's (company's) staff recognize near $50 \%$ of studied person. In performed studied through Nordic questionnaire, musculoskeletal disorders recognize with regards to various risk factors related to work. Therefore, the meaningfulness of this subject match with Joshi et al [31] that investigate duties and occupational type in occurring musculoskeletal disorders among industrial works, Alexopoulos [28], Looters and Burdof [33], macclure et al [34], Bos et al [35] and Thompson et al [36]. Risk factors that cause musculoskeletal disorders with their development include: excess force exertion, motion replays, force exertion in long time, continuous lifting heavy loads, push.

8 week hydrotherapy trainings had positive effect on decreasing neck disorders. In other words, hydrotherapy trainings cause improving subjects (participants) neck disorders that match with Andersen et al [37], Y linen et al [38], Rahnama [39]. With regards to training program that in current study presented isometric strength trainings and flexibility, it seems that training program have a positive effects on subjects (participants).

8 weeks hydrotherapy training have positive effects on reducing shoulders pain, in other word, training program improve concern (participants). Therefore with regards to this subject that in current research training program for shoulder insisted on muscle strength and flexibility, it seems that it has positive effect and improve subjects (participants) status and match with mac Macclure et al

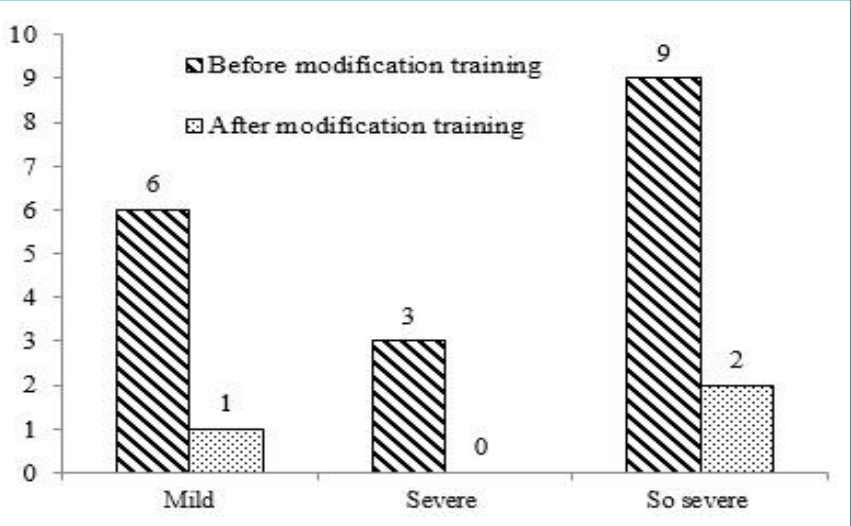

Figure 5: Information related to skeletal disorders in knee points.

[34] and European Agency for Safety and Heath at work [6] that point to trainings effect in reducing shoulder disorder and muscle strength and Rahnama et al studies [29], Karimiyan et al [39] and Jan Bozorgi et al [30]. 8 weeks hydrotherapy have positive effect on decreasing back pains, in other word, modification program develop subjects (participants) back pains status. With regards to special back training program which done from flexion training with emphasis on abdominal muscle's strengthening and back's extensors, it show that of total persons suffered from back's disorders, decrease to near (83.3)\% after doing (executing) training. This matter (subject) match with kofotolis [40] results that approve PNF training on trunk's muscle strength, flexibility and performance in persons with chronic back pain and reach to its result that PNF static and dynamic may be appropriate in improve short time strength of trunk's muscle and trunk's movement in persons with chronic back pain and also with Rahnama et al [29] Jan Bozorgi et al [30] studies.

8 weeks hydrotherapy trainings have a positive effect on knees' disorder improving. In other word, modified movements program leads to improve subject's knee pains and match with Gallis et al [41], Latifipour [31]. Even though, there is units called Health safety unit (HSE) that must control all of the work's ergonomic issues but due to lack of ergonomic educating to persons both in work's environment and life environment, these safety points won't run properly therefore, 
musculoskeletal disorders are significant in staff, with regards to that in this company, staff's sport problem controlled by concerned staffs and multiple clubs establish for staff's sport, due to lack of couches familiarity with musculoskeletal by these unit's coaches, none modification movement give to staffs, and presented training programs to stuffs increase musculoskeletal disorders, so we had to prohibit statistical sample from current sport files in club in executing modified movement. Current study's results show that hydrotherapy training in reducing musculoskeletal disorders of the police personnel have meaningful positive affect most of executed studies in long-time reach to aforementioned results. So current research findings from this point (view) that can show its effectiveness in short-time, can consider and execute hydrotherapy training application.

\section{References}

1. Chubineh A, Soleimani A, Daneshmand H, Mohamadbeigi A, Izdi Kh. Musculoskeletal disorders prevalence and posture evaluation with the method Rula in Shiraz public dentists in 2011. Dentistry journal of dentists Islamic society. 2013: 4: 22.

2. Melis M, Youssef $S$, Abou-Atme, Cottogono L, Pittua R. Upper body musculoskeletal symptom sin Sardinian dental students. J Can Dent Asso. 2004; 70: 306-310.

3. Shahnavaz H. Workplace injuries in the developing countries. Ergonomics 1987; 30: 397-404.

4. Jafary $\mathrm{T}, \mathrm{O}^{\prime} \mathrm{Neill} \mathrm{DH}$. The application of ergonomics in rural development: a review. Appl Ergon. 2000; 31: 263-268.

5. Bermander A, Bergman S. Non- pharmacological management of musculoskeletal disease in primary care. Best Pract Res Clin Rheumatol. 2008; 22: 563-577.

6. European Agency for Safety and Health at Work. Work-related musculoskeletal disorders: Prevention report. Luxembourg: Office for official publications of the European communities. 2008.

7. Buckle PW, Devereux JJ. The nature of work related neck and upper limb musculoskeletal disorders. Appl Ergon. 2002; 33: 207-217.

8. Punnett L, Wegman DH. Work-related musculoskeletal disorders: the epidemiologic evidence and the debate. J Electromyogr Kinesiol. 2004; 14: 13-23.

9. David G, Woods V, Li G, Buckle P. The development of the Quick Exposure Check (QEC) for assessing exposure to risk factors for work related musculoskeletal disorders. Appl Ergon. 2008; 39: 57-69.

10. Woods V. Work-related musculoskeletal health and social support. Occup Med (Lond). 2005; 55: 177-189.

11. Mattila M, Vilki M. OWAS Methods. In: Karwowski W, editor. The occupational ergonomics handbook: Interventions, controls, and applications in occupational ergonomics. New York: CRC Press; 2006.

12. Straker LM, O'Sullivan PB, Smith AJ, Perry MC. Relationships between prolonged neck/shoulder pain and sitting spinal posture in male and female adolescents. Man Ther. 2009; 14: 321-329.

13. Dankaerts WO, Sullivan PB, Burnett AF, Straker LM. Differences in sitting posture are associated with non-specific chronic low back pain disorders when patients are sub-classified. Spine. 2006; 31: 698- 704.

14. Cho CY. Survey of faulty postures and associated factors among Chinese adolescents. J Manipulative Physiol Ther. 2008; 31: 224-229.

15. Benzion A. Risk factors of prolonged sitting and lack of physical activity in related to postural deformities, muscles tension and backache among children. Budapest: Sommelweis University. 2004.

16. Shyasy Arani F. Study the amount of spinal musculoskeletal pain among workers of Siemens factory in Shiraz. [Thesis]. Shiraz: Shiraz University of Medical Sciences. 1998.
17. Soderberg GL. Surface Electromyography for Use in the Occupational Setting. In: Kasman GS, Cram JR, Wolf SL, Editors. Clinical applications in surface electromyography: chronic musculoskeletal pain. London: Aspen. 1998.

18. Habibi AH. Study spinal abnormalities among male workers of Ahvaz industry factories. [MSc Thesis]. Tehran: Tarbiat Modarres University; 1992.

19. Bergman B, Carlsson SG, Wright I. Women's work experiences and health in a male dominated industry. A longitudinal study. J Occup Environ Med. 1996; 38: 663-672.

20. Jin K, Sorock GS, Courtney TK. Prevalence of low back pain in three occupational groups in Shanghai, People's Republic of China. J Safety Res. 2004; 35: 23-28.

21. Omino K, Hayashi Y. Preparation of dynamic posture and occurrence of low back pain. Ergonomics. 1992; 35: 693-707.

22. Staal JB, Hlobil H, van Tulder MW, Koke AJ, Smid T, van Mechelen W. Returnto-work interventions for low back pain: a descriptive review of contents and concepts of working mechanisms. Sports Med. 2002; 32: 251-267.

23. Staal JB, Rainville J, Fritz J, van Mechelen W, Pransky G. Physical exercise interventions to improve disability and return to work in low back pain: current insights and opportunities for improvement. J Occup Rehabil. 2005; 15: 491 505.

24. Hayden JA, van Tulder MW, Tomlinson G. Systematic review: strategies for using exercise therapy to improve outcomes in chronic low back pain. Ann Intern Med. 2005; 142: 776-785.

25. Kasai R. Current trends in exercise management for choronic low back pain: comparison between strengthening exercise and segmental stabilization exercise. JPhys Ther Sci. 2006; 18: 97-105.

26. Abbassi $M$ and colleagues $B$. the effects of balance training in water and detraining on nerve-muscle function and healthy elderly men balance, Int Arch Occup Environ Health. 2013; 75-89.

27. Bos E, Krol B, Van der star L, Groothoff J. Risk factors and musculoskeletal complaints in non-specialized nurses 'IC nurses 'operation room nurses 'and X-ray technoligists. Int Arch Occup Environ Health. 2007; 80: 198-206.

28. Alexopoulos E C, Tanagra D, Konstantinou E, Burdorf A. Musculoskeletal disorders in shipyard industry: prevalence 'health care use 'and absenteeism. BMC Musculoskeletal Disorder. 2006; 24: 70-88.

29. Rahnama N, Bambaei, Chi, A, Reiyasti, F. The effect of 8 week modified movement of worker's musculoskeletal disorders, Iran's glaze factory with ergonomic intervention, Isfahan's medical college journal. 2011; 326: 108316.

30. Jan bozorgi A, Karimi A, Rahnama N, Karimiyan R, Ghasemi, Gh. Ergonomic evaluation of teacher's musculoskeletal disorders risk with the method of fast evaluation and confrontation (QEC), the effects of 8 weeks selected modified movement and occupational ergonomic interventions on their confrontation rate. Research in rehabilitation science. 2013; 8: 5-15.

31. Latifipour F. 2003. Evaluation of confrontation rate with musculoskeletal disorder on women's worker of pharmacy factories with the method of QEC and investigating effect on appropriate intervention. Master's thesis of professional health of Tarbiat Modarres university's medicine collage. 120pp.

32. Joshi T K, Menon K K, Kishore J. Musculoskeletal disorders industrial workers of Delhi. Int J Occup Environ Health. 2001; 7: 217- 221.

33. Looters F, Burdorf A. Prognostic factors for duration of sickness absence due to msculoskeletal disorders. Clin J Pain. 2006; 22: 212-221.

34. Macclure PHW. Shoulder function and 3-dimensional kinematics in people with shoulder impingement syndrome before and after a 6-week exercise program. Physical ipy. 2004; 84: 832-848.

35. Bos E, Krol B, Van der star L, Groothoff J. Risk factors and musculoskeletal complaints in non-specialized nurses, IC nurses, operation room nurses and X-ray technologists. Int Arch Occup Environ Health. 2007; 80: 198-206.

36. Thomsen JF. Risk factors for hand-wrist disorders in repetitive work. Occup Environ Med. 2007; 64: 527-533. 
37. Andersen $\mathrm{JH}$, Haaher JP, Frost $\mathrm{P}$. Risk factors for more severe regional musculoskeletal symptoms: a two-year prospective study of a genera working population. Arthritis Rheum. 2007; 56: 1355-1364.

38. Ylinen JJ, Takala EP, Nykanen MJ, Kautiainen HJ, Hakkinen AH, Airaksinen OV. Effects of twelve-month strength training subsequent to twelve-month stretching exercise in treatment of chronic neck pain. J Strength Cond Res. 2006; 20: 304-308.

39. Karimiyan R, Rahnama N, Habbi A, Ghasemi Gh, Karimiyan M. The effect of modification training on musculoskeletal disorders. The journal of safety system researches. 2011; 6: 10-25.
40. Kofotolis N, Kellis E. Effects of two 4-week proprioceptive neuromuscular facilitation programs on muscle endurance flexibility and functiona performance in women with chronic low back pain. Physical Therapy. 2006; 86: 1001-1012.

41. Gallis $\mathrm{CH}$. Work-Related musculoskeletal symptoms among Greek forest workers. International Journal of Industrial Ergonomics. 2006; 36: 731-736.
Austin J Musculoskelet Disord - Volume 4 Issue 2 - 2017

ISSN : 2381-8948 | www.austinpublishinggroup.com

Dolatabadi et al. (C) All rights are reserved
Citation: Dolatabadi NH, Rahnama N and Tavakol N. The Effect of Hydrotherapy Training on Function Occupational Toofal Sanat Consulting Engineers. Austin J Musculoskelet Disord. 2017; 4(2): 1044 